\title{
A study of Inhibin $\alpha-16 C>$ T gene polymorphism and other reproductive hormones in the diagnosis of Premature Ovarian Failure in Egyptian Women undergoing ICSI
}

Abdel Aziz El-Refaay*, Azza M. El-Wakf ', Amal K. Selim², Ayman Z. Elsammandouy², Hosam AbdelFatah3, Shimaa M. Saad? 'Zoology Department, Physiology Division, Faculty of Science, Mansoura University, Egypt: ${ }^{2}$ Biochemistry Department Faculty of Medicine, Mansoura University, Egypt; ${ }^{3}$ Obstetrics and Gynecology Department, Faculty of Medicine, Mansoura University, Egypt.
Abdel Aziz El Refaeey

Professor of Obstetrics and

Gynecology Department, Faculty of Medicine, Mansoura University, Egypt.

$(+2) 01007516153$

\begin{abstract}
Background: Premature ovarian failure (POF) or poor ovarian response is a syndrome characterized by amenorrhea for duration of 4-6 months or more, hypo-estrogenism and elevated serum FSH concentration (FSH $\geq 40 \mathrm{IU} / \mathrm{l}$ ) before age of 40 years. The POF may arise through different events including: reduction of primordial follicle pool; acceleration of follicular atresia; alteration of primordial follicles maturation/recruitment. Inhibin is a product of granulosa cells. Onset of POF can be a result of inhibin alpha genetic abnormalities, the most extensively studied genetic abnormality is $16 \mathrm{C}>\mathrm{T}$ polymorphism.
\end{abstract}

Objectives: The present study was undertaken to evaluate whether INH $\alpha-16 \mathrm{C}>\mathrm{T}$ gene polymorphism could be a predictive marker for POF in the Egyptian females undergoing ICSI. Also, to identify role of the ovarian hormones like; FSH, LH, estradaiol, progesterone, anti-mullarian hormone, activin and inhibin in the dignosis of POF.

Patients and methods: All cases were recurted from the Gynecology and Obstetric Department, Mansoura University, Egypt. All women were subjected to history taking including demographic data, menstrual and reproductive characteristics and history of hormonal therapy. The study group included 50 women with symptoms and signs suggestive of ovarian failure; their mean age was $31.5 \pm 4.88$ years. The control group included 50 healthy women with normal hormonal profile with male factors infertility, their mean age $29.05 \pm 3.3$ years. Venous blood samples were collected for assay of follicle stimulating hormone (FSH), luteinizing hormone ( $\mathrm{LH})$, antimullarian hormone (AMH), inhibin and activin using enzyme linked immunosorbent assay. Genomic DNA was isolated from EDTAanticoagulated peripheral blood using DNA extraction kit.

Results: Women with POF showed a highly significant increase in the mean FSH and LH levels compared to control group. There is a statistically significant decrease of the mean serum inhibin and inhibin/activin ratio in women with POF compared to control women. In women with POF, the frequencies of homozygous genotypes CC, heterozygote genotypes CT and homozygote genotypes TT of the INH $\alpha-16 \mathrm{C}>\mathrm{T}$ polymorphism were $70 \%(35 / 50), 24 \%(12 / 50)$ and $6 \%(3 / 50)$. The C allele was present in $82 \%$ of patients with POF and in $73 \%$ of the control group, whereas the T allele was present in $12 \%$ and $27 \%$ respectively. Conclusion: INH $\alpha-16 \mathrm{C}>\mathrm{T}$ gene polymorphisms is not considered as a risk factor for POF among Egyptian women.

Key Words: ovarian follicle, premature ovarian failure, autoimmune causes, reproductive hormones. 


\section{INTRODUCTION}

Premature ovarian failure (POF), or poor ovarian response is a syndrome characterized by amenorrhea for duration of 4-6 months or more, hypo-estrogenism and elevated serum FSH concentration $(\geq 40 \mathrm{IU} / \mathrm{l})$ before age of 40 years ${ }^{(1)}$.

Women with POF can experience multiple consequences of hypo-estrogenism including, osteoporosis, accelerated cardiovascular and neurocognitive disorders ${ }^{(2)}$.

However, the major consequence of POF is lowered fertility through: reduction of primordial follicle pool; acceleration of follicular atresia; or alteration of primordial follicles maturation/ recruitment ${ }^{(3,4)}$.

There may be a number of contributing factors for POF, including genetic abnormalities, pelvic surgery and chemotherapy or other medications ${ }^{(5)}$.

In most cases, FSH and LH may be considered as a contributing factors dealing with oocyte atresia ${ }^{(8)}$. Also the role of ovarian hormones; estradiol (E2), progesterone, anti-mullerian hormone (AMH), activin and inhibin may be responsiblein the depletion of the primordial follicular $\operatorname{pool}^{(6)}$.

Inhibin has been implicted as a hormonal candidate in the mechanistic determinants of POF disease. Inhibin is a hormonal product of granulosa cells( 7 ,

8 ) that serves as marker of ovarian function and/ or follicular development because of its role in negative feedback control of $\mathrm{FSH}^{(9)}$.

Inhibin is a heterodimer glycoprotein consisting of two subunits (18 kDa-alpha) and (14 kDa- beta) linked by disulphide bonds to generate two forms of inhibins (A\&B). Each form has a common alpha subunit ( $\alpha$-subunit) which is attached to either beta subunits $(\beta A)$ or $(\beta B)$ to form inhibin $A(\alpha-\beta A)$ and inhibin $B(\alpha-\beta B)$. Inhibin subunits are encoded by three separate genes: INH $\alpha$, INH $\beta$ A and INH $\beta B$, which map to 2q33-q36, 2cen-q13 and 7p15-p14, respectively ${ }^{(10)}$.

Inhibin $\alpha$ (INH $\alpha)$ found on chromosome 2 (2q33-q36) is the gene encodes the alpha subunits of inhibin A and inhibin B. The INHa genetic variants have suggested to be responsible for less bioactive and decreased circulating inhibin levels, causing an increase in FSH levels, with increased follicle recruitment, elevated follicle depletion and increased susceptibility for developing $\mathrm{POF}^{(11)}$.
$\mathrm{INH} \alpha$ gene $16 \mathrm{C}>\mathrm{T}$ polymorphism are the most extensively studied. However, controversial results were obtained. Marozzi et al.(12) examined $-16 \mathrm{C}>\mathrm{T}$ INH $\alpha$ gene polymorphism and illustrated lowered frequency of $\mathrm{T}$ allele in the Italian POF patients compared to control populations.

Other study by Sundblad et al. ${ }^{(13)}$ showed no association between -16T allele and prevalence of POF among the Argentinean women.

Moreover, in Korean women there was a contrasting results. Data from Yoon et al. ${ }^{(14)}$ suggested no association between $\mathrm{INH} \alpha$ gene polymorphism $-16 \mathrm{C}>\mathrm{T}$ and risk of POF, whereas evidence from Kim et al. ${ }^{(15)}$ supported that this polymorphism is a contributing factor.

Accordingly, the present study was undertaken to evaluate whether INH $\alpha-16 \mathrm{C}>\mathrm{T}$ gene polymorphism could be a predictive marker for POF in the Egyptian females undergoing ICSI. Also, to identify role of the ovarian hormones like; FSH, LH, E2, progesterone, AMH, activin and inhibin in the diagnosis of this disease

\section{PATIENTS AND METHODS}

This study was conducted over a period of 3 years from January 2014 till December 2016. All patients were recruited from the outpatient clinic of Obstetrics and Gynecology Department, Mansoura University, Egypt. An informed consent was taken from each participant.

\section{Groups:}

Women were divided into two groups. The study group included 50 women diagnosed with premature ovarian failure (POF), defined as cessation of menses for duration of 6 months or more before age of 40 years and serum FSH measurements $\geq 40 \mathrm{mIU} / \mathrm{ml}$, their mean age $\pm \mathrm{SD}$ was $31.5 \pm 4.88$ years. The ICSI trial was done in the previous 3 months.

All patients were subjected to history taking (age and weight), menstrual history (age at menarche, menstrual history, and duration of infertility), obstetric history and history of hormonal medication. Clinical examination to exclude other causes of infertility, endocrine disorders (hyper or hypothyroidism and hyperprolatinaemia). The control group included 50 women, undergoing ICSI due to male factors, their mean age $29.05 \pm 3.3$ years. 


\section{Methods:}

- Five ml venous blood was collected without anticoagulant for measurements of serum FSH, $\mathrm{LH}, \mathrm{AMH}$, inhibin and activin in the 3rd day of menstrual cycle.

All samples were assayed in duplicate using a commercial ELISA kits according to manufacturer's instructions.

- Three $\mathrm{ml}$ venous blood sample was collected from each case in ethyle diamine tetracetic acid (EDTA) tube for DNA extraction and study of inhibin $\alpha$ gene (INH $\alpha-16>$ CT) polymorphism by RFLP.PCR method.

\section{DNA extraction:}

Genomic DNA was isolated using DNA extraction kit (Qia-ampilification extraction kit -Qiagene, USA).

\section{Polymerase Chain Reaction (PCR):}

Enzymatic amplification was performed by PCR using Taq polymerase enzyme and T-Gradient thermal cycler (Biometra, Germany). PCR mixture (total volume $50 \mu \mathrm{l}$ ) was prepared in thin wall PCR tube for each sample.

PCR products were analyzed for restriction fragments length polymorphism (RFLP) by using $5 \mathrm{U}$ of SpeI restriction enzyme (New England Biolabs, Ipswich, $\mathrm{MA}, \mathrm{USA}$ ) at $37^{\circ} \mathrm{C}$ over night.

Electrophoresis of $5 \mu \mathrm{l}$ of each PCR product was done after amplification by using $1.5 \%$ agarose gel to ensure the presence of wanted size, then visualized via Light UV Trans illuminator (Model TUV-20, OWI Scientific, Inc. 800 242-5560, France) and photographed.

\section{Statistical analysis:}

Data were analyzed using the computer program SPSS (Statistical package for social science) version 17.0.

Descriptive statistics were calculated in the form of mean \pm SD and frequency (number and percent), Student's t-test and Analysis Of Variance (ANOVA). Inter-group comparison of categorical data was performed by using chi square test (X2-value).

Polymorphisms and genotype frequencies were evaluated by gene counts. The data were tested for the goodness of fit between the observed and expected genotype frequencies (X2 test). When the observed genotype frequencies fit to HardyWeinberg equilibrium, X2 tests (2-by-2 tables) were performed to calculate significantly different genotype distributions between patients and controls and also odd's ratio(OR) and confidence interval95\% were calculated to detect risk ratio.

Pearson correlation coefficient test was used correlating different parameters.

$\mathrm{P}$ value $<0.05$ was considered a statistically significant.

\section{RESULTS}

In the present study, there was no statisticaly signifcant difference in their mean age and body weight related to control group. For number of oocyte, there are statistically significant differences were observed in the patients compared to control group, $(3.42 \pm 1.18)$ in women with POF and $(9.64$ \pm 1.94 ) in control women (table 1).

As shown in table 2, all women with POF exhibited significant increase in FSH and LH levels compared to level in the control women.

The mean AMH levels were elevated or within normal range level in the control group, but in patient group, the mean $\mathrm{AMH}$ was decreased in the study group.

As illustrated in table (3), the study group showed a statistically significantly decrease in the serum inhibin level $(28.91 \pm 9.59)$ when compared to control group (77.29 \pm 17.95$),(\mathrm{P}<0.001)$. Moreover, the results of the current study reveal non-significant $(\mathrm{P}=0.13)$ change of serum activin in the patients group that exhibited mean values $(17.04 \pm 1.88)$ in comparison to the control group with mean values (17.76 \pm 2.73$)$. The inhibin/activin ratio shows significant decreasing in patient group when compared to control group with $(\mathrm{P}<0.001)$.

The results of INH $\alpha-16 \mathrm{CT}$ genotype and allele frequencies are presented in table 4 . The homozygote (CC) was the dominating genotype in the group of women with poor ovarian response $70.0 \%(35 / 50)$ and the control group $52.0 \%(26 / 50)$. Regarding the alleles, allele $\mathrm{C}$ was present in $82 \%$ of the patient with poor ovarian response and in $73 \%$ of the control group whereas allele $\mathrm{T}$ was present in $12 \%$ and $27 \%$ respectively, all patients with poor ovarian response and women in control group, showing nonsignificant differences in the allelic distribution of women with poor ovarian response related to control group, $(\mathrm{P}=0.12, \mathrm{OR}=0.6$ and $95 \% \mathrm{CI}=0.3-1.16)$. 
Table (8): Inhibin assay of the study subjects according to their INH $\alpha$-16CT genotype

\begin{tabular}{|c|c|c|c|c|c|}
\hline \multirow{2}{*}{\multicolumn{2}{|c|}{ Inhibin }} & \multicolumn{3}{|c|}{ Genotyping } & \multirow{2}{*}{ P1 } \\
\hline & & $\mathbf{C C}$ & CT & TT & \\
\hline \multirow{2}{*}{ Control } & Mean & 76.28 & 81.10 & 59.38 & \multirow{2}{*}{0.13} \\
\hline & \pm SD & 19.04 & 16.49 & 0.39 & \\
\hline \multirow{3}{*}{ Patients } & Mean & 29.24 & 27.89 & 29.24 & \multirow{2}{*}{0.92} \\
\hline & \pm SD & 10.14 & 9.40 & 3.05 & \\
\hline & P2 & $<0.001$ & $<0.001$ & $<0.001$ & \\
\hline
\end{tabular}

SD: standard deviation P:Probability $\quad$ P significant when $<0.05$

P1: significance between CC, CT and TT in either control or patient groups(Test used:One way ANOVA) P2: significance between Control and patient groups in different genotping CC, CT and TT(Test used: Student's t-test)

Table (9): Activin assay of the study subjects according to their INH $\alpha$-16CT genotype

\begin{tabular}{|l|l|c|c|c|c|}
\hline \multicolumn{2}{|c|}{ Activin } & \multicolumn{3}{c|}{ Genotyping } & \multirow{2}{*}{ P1 } \\
\cline { 3 - 5 } \multicolumn{2}{|c|}{ Control } & CC & CT & TT & \multirow{2}{*}{0.23} \\
\cline { 2 - 5 } & \pm SD & 18.26 & 16.99 & 18.80 & 3.77 \\
\hline \multirow{2}{*}{ Patients } & Mean & 2.59 & 2.72 & 18.03 & \multirow{2}{*}{0.5} \\
\cline { 2 - 5 } & \pm SD & 17.09 & 16.64 & 1.10 & \\
\hline & P2 & 2.01 & 1.60 & 0.75 & \\
\hline
\end{tabular}

SD: standard deviation P:Probability $\quad$ P significant when $<0.05$

Table (10): I/A assay of the study subjects according to their INH $\alpha$-16CT genotype

\begin{tabular}{|c|c|c|c|c|c|}
\hline \multirow{2}{*}{\multicolumn{2}{|c|}{ I/A ratio }} & \multicolumn{3}{|c|}{ Genotyping } & \multirow{2}{*}{ P1 } \\
\hline & & \multirow{2}{*}{$\begin{array}{c}\text { CC } \\
4.48\end{array}$} & \multirow{2}{*}{$\begin{array}{c}\mathbf{C T} \\
4.81 \\
\end{array}$} & \multirow{2}{*}{$\frac{\text { TT }}{3.30^{\mathrm{b}}}$} & \\
\hline Control & Mean & & & & 087 \\
\hline Comtroi & \pm SD & 0.97 & 0.88 & 0.17 & 0.01 \\
\hline \multirow{2}{*}{ Patients } & Mean & 1.63 & 1.59 & 1.59 & \multirow{2}{*}{0.19} \\
\hline & \pm SD & 0.45 & 0.38 & 0.19 & \\
\hline & P2 & $<0.001$ & $<0.001$ & $<0.001$ & \\
\hline
\end{tabular}

SD: standard deviation $\quad$ P:Probability $\quad$ P significant when $<0.05$

P1: significance between CC, CT and TT in either control or patient groups(Test used:One way ANOVA) b: significance between TT and CT

P2: significance between Control and patient groups in different genotping CC, CT and TT(Test used: Student's t-test). 
Table (11): Comparison of hormonal assay according to genotyping alleles

\begin{tabular}{|c|c|c|c|c|c|c|c|}
\hline & \multicolumn{4}{|c|}{ Alleles } & \multirow{3}{*}{ P1 } & \multirow{3}{*}{ P2 } \\
\hline & & \multicolumn{2}{|c|}{$\mathrm{C}$} & \multicolumn{2}{|c|}{$\mathbf{T}$} & & \\
\hline & & FSH & LH & FSH & LH & & \\
\hline \multirow{2}{*}{ Control } & Mean & 6.34 & 6.69 & 7.23 & 7.00 & \multirow{2}{*}{0.049} & \multirow{2}{*}{0.38} \\
\hline & $\pm \mathrm{SD}$ & 1.99 & 1.60 & 1.95 & 1.52 & & \\
\hline \multirow{3}{*}{ Patients } & Mean & 12.95 & 9.50 & 12.38 & 9.09 & \multirow{2}{*}{0.16} & \multirow{2}{*}{0.3} \\
\hline & $\pm \mathrm{SD}$ & 1.65 & 1.54 & 1.14 & 1.43 & & \\
\hline & P4 & $<0.001$ & $<0.001$ & $<0.001$ & $<0.001$ & & \\
\hline
\end{tabular}

\begin{tabular}{|c|c|c|c|c|c|c|c|c|c|c|}
\hline & \multicolumn{6}{|c|}{ Alleles } & \multirow{3}{*}{ P1 } & \multirow{3}{*}{$\mathbf{P 2}$} & \multirow{3}{*}{ P3 } \\
\hline & & \multicolumn{3}{|c|}{$\mathrm{C}$} & \multicolumn{3}{|c|}{$\mathbf{T}$} & & & \\
\hline & & inhibin & activin & I/A ratio & inhibin & activin & $\begin{array}{l}\text { I/A } \\
\text { ratio }\end{array}$ & & & \\
\hline \multirow[t]{2}{*}{ Control } & Mean & 77.67 & 17.89 & 4.57 & 76.28 & 17.39 & 4.47 & \multirow{2}{*}{0.7} & \multirow{2}{*}{0.4} & \multirow{2}{*}{0.6} \\
\hline & $\pm \mathrm{SD}$ & 18.22 & 2.65 & .95 & 17.14 & 2.91 & 1.00 & & & \\
\hline \multirow[t]{3}{*}{ Patients } & Mean & 29.04 & 17.03 & 1.62 & 28.34 & 17.11 & 1.59 & \multirow{2}{*}{0.77} & \multirow{2}{*}{0.87} & \multirow{2}{*}{0.78} \\
\hline & $\pm \mathrm{SD}$ & 9.93 & 1.94 & .43 & 7.73 & 1.55 & .32 & & & \\
\hline & P4 & $<0.001$ & 0.02 & $<0.001$ & $<0.001$ & 0.7 & $<0.001$ & & & \\
\hline
\end{tabular}

SD: standard deviation P:Probability $\quad$ P significant when $<0.05$

P1: significance between C and T alleles in inhibin either control or patient groups(Test used: Student's t-test)

P2: significance between $\mathrm{C}$ and $\mathrm{T}$ alleles in activin either control or patient groups(Test used: Student's t-test)

P3: significance between C and T alleles in FSH either control or patient groups(Test used: Student's t-test)

P4: significance between Control and patient groups in either C or T alleles (Test used: Student's t-test)

\section{DISCUSSION}

Females diagnosed with POF are characterized by early loss of ovarian function, with failure to produce adequate follicles, increased risk of infertility and it is associated with a significantly lowered possibility of pregnancy. This brings out marked difficulty for proceeding in-vitro fertilization (IVF) a type of assisted reproduction techniques, where a large number of oocytes are desirable $\left.{ }^{(16,}, 17\right)$.

In most cases, the main features of POF included, stopped menstruation for at least 6 months accompanied by rise in serum level of FSH $(\geq$ $40 \mathrm{IU} / \mathrm{l})$ resulting in menopause pattern starting before age of 40 years $^{(2)}$.

Women with raised FSH level always exhibit lowered ovarian reserve and reduced pregnancy rate with IVF technique, independent of age ${ }^{(18)}$.
Loutradis et al. ${ }^{(19)}$ also showed that women with unexplained infertility, but with higher serum FSH concentration are at risk of developing ovarian failure within short time.

In the present study, tested females with POF showed highly significant increases in FSH and LH hormones compared to control group which in turn may lead to decreased number of oocytes and poor response during ovulation induction confirming that both FSH and LH can be used as monitoring indicators for ovarian dysfunction with lesser probability for ovulation and pregnancy ${ }^{(20)}$.

Additionally; affected women with POF have very low levels of circulating estrogens. Because of a failure of estrogen production by the ovary before age 40 years, the pituitary reacts by making more FSH traying stimulate the ovaries to produce estradiol $^{(3)}$. 
In women with POF, the ovaries: stop releasing eggs, or release them only intermittently, and stop producing the hormones estrogen and progesterone, or produce them only intermittently ${ }^{(3)}$.

Circulating levels of estrogen and progesterone produced by the ovary are low, whereas the serum levels of gonadotropins released from the pituitary are high due to the loss of feedback inhibition by the ovarian steroid hormones ${ }^{(23)}$.

For progesterone hormone, the present study demonstrated significant decrease on comparing each of women with POF to corresponding control, as in agreement with findings of Sundblad et al. ${ }^{(16)}$.

Anti-Müllerian hormone (AMH) has been suggested as a more accurate indicator of the presence of ovarian follicles. POF patients have significantly lowered AMH hormone levels compared to control group and showed poor response to IVF cycle $^{(22)}$.

Similar findings were also detected in the present study regarding the association between lowered $\mathrm{AMH}$ and POF patients with lowered number of oocytes. Eldar-Geva et al. ${ }^{(23)}$ reported that poor responders had significantly lowered AMH levels compared with normal responders.

The dysfunction of AMH production in the antral follicles of POF women observed in series of ovarian biopsies suggested the possibility of the presence of a defect in antral follicular development, particularly concerning the granulosa cells. A decreased AMH production could alter the mechanism of follicular recruitment in these patients. AMH could be useful in discriminating POF patients with a sizable follicular population from patients with no or few ovarian follicles, with a lesser potential for ovulation and pregnancy ${ }^{(22)}$.

Inhibin and activin are closely related gonadal hormones, structurally belonging to the transforming growth factor (TGF)- $\beta$ superfamily. Activin can directly stimulate FSH biosynthesis and secretion, whereas inhibin can negatively regulate these effects by blocking synthesis and secretion of FSH. Diminished levels of dimeric inhibin at the menopausal transition time, with increase in activin A, could be the main reason for high levels of FSH characteristic for late reproduction ${ }^{(24)}$.

The present study showed significantly lowered serum inhibin and inhibin/activin ratio in women with POF on comparing to control women, whereas level of activin was within normal range as in control. Comparable results were observed by Munz et al. ${ }^{(25)}$, suggesting the association between lowered serum inhibin and the development of POF disease.

At the molecular level, several studied have indicated a relation between INH $\alpha$ gene polymorphisms and the decline in inhibin bioavailability, resulting in premature depletion of ovarian function ${ }^{(1)}$.

Subsequent studies were performed in Korean women with contrasting results. Yoon et al. ${ }^{(14)}$ suggested no association of $\mathrm{INH} \alpha$ gene polymorphism $(16 \mathrm{C}>\mathrm{T}$ ) with risk of $\mathrm{POF}$, whereas evidence from Kim et al. ${ }^{(16)}$ supported these polymorphisms with POF disease.

Others reported by Kim et al. ${ }^{(16)}$. Similar results were evidenced by Yoon et al. ${ }^{(14)}$.

In the present study, the analysis of INH $\alpha-16 \mathrm{C}>\mathrm{T}$ gene polymorphism in the studied females with POF was demonstrated, where the frequencies of homozygous genotypes $\mathrm{CC}$, heterozygote genotypes CT and homozygote genotypes TT of the INH $\alpha-16 \mathrm{C}>\mathrm{T}$ polymorphism were $70 \%(35 / 50)$, $24 \%(12 / 50)$ and $6 \%(3 / 50)$. However among the fertile control women, the genotypes $\mathrm{CC}, \mathrm{CT}$ and TT were $52.0 \%(26 / 50), 42.0 \%(21 / 50)$ and $6.0 \%(3 / 50)$ respectively, showing no significant variation in the genotypes distribution of women with POF compared to control group $[\mathrm{P}=0.052$, $\mathrm{OR}=0.24$ and $95 \% \mathrm{CI}=0.17-1.02]$ in genotype $\mathrm{CT}$ and $[\mathrm{P}=1.00, \mathrm{OR}=0.74$ and $95 \% \mathrm{CI}=014-3.98]$ in genotype TT.

Considering the allelic frequencies, the present study indicated that, C allele was presented in $82 \%$ of patients with POF and in $73 \%$ of the control group, whereas $\mathrm{T}$ allele was presented in $12 \%$ and $27 \%$ respectively, showing non-significant differences in the allelic distribution between the two studied groups $(\mathrm{P}=0.12, \mathrm{OR}=0.6$ and $95 \% \mathrm{CI}=0.3-1.16)$.

Woad et al.(26) examined -16C $>\mathrm{T}$ polymorphism and showed that the frequency of the $\mathrm{T}$ allele was significantly decreased in POF patients compared to control group. As such, significant reductions in frequency of -16T allele were detected in New Zealand and Slovenia POF, indicating that $\mathrm{INH} \alpha$ $-16 \mathrm{C}>\mathrm{T}$ polymorphism is associated with the development of POF. 
Nevertheless, other studies were unable to support these findings in a large sample of Italian and German populations ${ }^{(5)}$.

Considering these results and others detected in this study, it can postulate that $-16 \mathrm{C}>\mathrm{T}$ INH $\alpha$ polymorphism may serve as a susceptibility factor for POF in several populations, however this polymorphism was not found to affect the disease in others, indicating that ethnic variations might influence the pattern of $-16 \mathrm{C}>\mathrm{T}$ INH $\alpha$ polymorphism in the POF patients.

\section{CONCLUSION}

Based on the current data, INH $\alpha-16 \mathrm{C}>\mathrm{T}$ gene polymorphisms seemed not to account for incidence of POF among studied Egyptian women, suggesting that other gene variants may be involved in this respect. Additional studies with larger number of Egyptian POF patients are recommended for identifying responsible genetic variants, which may facilitate putative therapy for POF patients.

\section{$\underline{\text { References }}$}

1. Chapman, C.; Cree, L.; Shelling, A.N. The genetics of premature ovarian failure: current perspectives. International Jouranal of Women's Health. 2015, 7:799-810.

2. Podfigurna-Stopa, A.; Czyzyk, A.; Grymowicz, M.; Smolarczyk, R.; Katulski, K.; Czajkowski, K.; Meczekalski, B. Premature ovarian insufficiency: the context of long term effects. J. Endocrinol. Invest 2016. 39: 983-990.

3. Nelson, L.M. Clinical practice, primary ovarian in sufficiency. N. Engl. J. Med. 2009; 360: 606-614.

4. Persani, L.; Rossetti, R.; Cacciatore, C.; Bonomi, M. Genes involved in human premature ovarian failure. Journal of Molecular Endocrinology 2010, 45: 257-279.

5. Nuovo, S.; Passeri,L.; Di Benedetto, E.; Calanchini, M.; Meldolesi, I.; Di Giacomo, M.C. Characterization of endocrine features and genotype-phenotypes correlations in blepharophimosis-ptosis-epicanthus inversus syndrome type 1. J. Endocrinol. Invest. 2016; 39(2): $227-233$.

6. Shelling, A.N. Premature ovarian failure. Reproduction 2010, 140:633-41.

7. Massin, N.; Gougeon, A.; Meduri, G.; Thibaud, E.; Laborde, K.; Matuchansky, C. Ovarian histology in the management of patients presenting a premature ovarian failure. Hum. Reprod. 2004, 19, 2555-2560.

8. Luisi, S.; Orlandini, C.; Regini, C.; Pizzo, A.; Vellucci, F.; Petraglia, F. Premature ovarian insufficiency: from pathogenesis to clinical management. J. Endocrinol. Invest. 2015, 38(6):597-603.

9. Walton, K.L.; Kelly, E.K.; Johnson, K.E.; Robertson, D.M.; Stanton, P.G.; Harrison, C.A. A Novel, more efficient approach to generate bioactive inhibins. Endocrinology 2016, 157(7): 2799-2809.

10. Fallahian, M.; Pouresmaeili, F.; Azizi, F.; Zali, M.R.; Samani, E.M.; Kharaziha, P. Existence of Inhibin $\alpha$-Subunit Gene Mutation in a Population of Iranian Women with Premature Ovarian Failure. Int. J. Endocrinol. Metab. 2009, 2: 67-71.
11. Shelling, A.N. Mutations in inhibin and activin genes associated with human disease. Mol. Cell. Endocrinol 2012, 359:113-20.

12. Marozzi, A.; Porta, C.; Vegetti, W.; Crosignani, P.G.; Tibiletti, M.G.; Dalprà, L.; Ginelli, E. Mutation analysis of the inhibin alpha gene in a cohort of Italian women affected by ovarian failure. Hum. Reprod. 2002, 17: 1741-5.

13. Sundblad, V.; Chiauzzi, V.A.; Andreone, L.; Campo, S.; Charreau, E.H.; Dain, L. Controversial role of inhibin alpha-subunit gene in the aetiology of premature ovarian failure. Hum. Reprod. 2006, 21: 1154-60.

14. Yoon, S.H.; Choi, Y.M.; Hong, M.A.; Kim, J.J.; Im, H.J.; Lee, G.H. et al. Inhibin alpha gene promoter polymorphisms in Korean women with idiopathic premature ovarian failure. Hum. Reprod. 2012, 27: 1870-3.

15. Kim, H.; Chun, S.; Gu, B.S.; Ku, S.Y.; Kim, S.H.; Kim, J.G. Relationship between inhibin alpha gene polymorphisms and premature ovarian failure in Korean women. Menopause 2011, 18: 1232-6.

16. Shanbhag, S.; Aucott, L.; Bhattacharya, S.; Hamilton, M A.; McTavish, A.R. Interventions for "poor responders to controlled ovarian hyperstimulation $(\mathrm{COH})$ in invitro fertilization (IVF). Cochrane Database Syst Rev. 2007, 1: CD004379.

17. Venetis, C.A.; Kolibianakis, E.M.; Tarlatzi, T.B. Tarlatzis, B.C. Evidence-based management of poor ovarian response. Ann. N. Y. Acad. Sci. 2010, 1205 199-206.

18. Badawy, A.; Wageah, A.; El Gharib, M.; Osman, E.E Prediction and Diagnosis of Poor Ovarian Response The Dilemma. J Reprod Infertil. 2011, 12(4): 241-248.

19. Loutradis, D.; Drakakis, P.; Vomvolaki, E.; Antsaklis, A Different ovarian stimulation protocols for womenwith diminished ovarian reserve. J. Assist. Reprod. Genet. 2007, 24: 597-611.

20. Gao, J.; Tiwari-Pandey, R.; Samadfam, R.; Yang, Y. Miao, D.; Karaplis A.C.; Sairam, M.R.; Goltzman, D. Altered ovarian function affects skeletal homeostasis independent of the action of follicle-stimulating hormone. Endocrinology 2007, 148: 2613-21.

21. Méduri, G.; Massin, N.; Guibourdenche, J.; Bachelot. A.; Fiori, O.; Kuttenn, F.; Misrahi, M.; Touraine, P. Serum anti-Müllerian hormone expression in women with premature ovarian failure. Human Reproduction 2007; 22(1): 117-123.

22. Eldar-Gava, T.; Robertson, D.M.; Cahir, N. Relationship between serum inhibin $\mathrm{A}$ and $\mathrm{B}$ and ovarian follicle developments after a daily fixed dose administration of recombinant follicle-stimulating hormone. J. Clin. Endocrinol. Metab. 2005, 85: 607-613.

23. Cordts, E.; Christofolini, D.; Amaro dos Santos, A.: Bianco, B.; Barbosa, C. Genetic aspects of premature ovarian failure: a literature review. Arch. Gynecol. Obstet. 2011; 283:635-643.

24. Munz, W.; Hammadeh, M.E.; Seufert, R.; Schaffrath, M.; Schmidt, W.; Pollow, K. Serum inhibinA, inhibin $\mathrm{B}$, pro-alpha $\mathrm{C}$, and activin A levels in women with idiopathic premature ovarian failure. Fertil.Steril. 2004; 82: $760-2$.

25. Woad, K.J.; Pearson, S.M.; Harris, S.E.; Gersak, K.; Shelling, A.N. Investigating the association between inhibin alpha gene promoter polymorphisms and premature ovarian failure. Fertil.Steril. 2009, 91: 62-6. 